
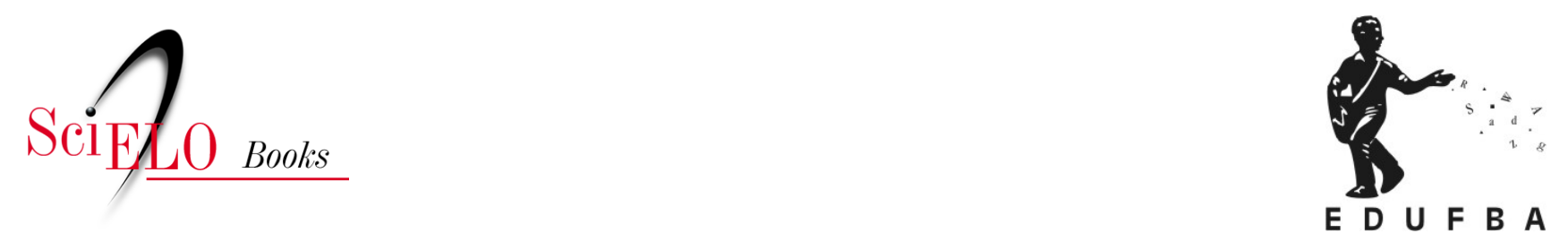

\title{
Sintomas vocais e absenteísmo em teleoperadores sindicalizados
}

\author{
Flávia Silva Santa Mônica \\ Maria Lúcia Vaz Masson \\ Tânia Maria de Araújo
}

\section{SciELO Books / SciELO Livros / SciELO Libros}

MÔNICA, F.S.S., MASSON, M.L.V., and ARAÚJO, T.M. Sintomas vocais e absenteísmo em teleoperadores sindicalizados. In: FERNANDES, R.C.P., LIMA, M.A.G., and ARAÚJO, T.M., comps. Tópicos em saúde, ambiente e trabalho: um olhar ampliado [online]. Salvador: EDUFBA, 2014, pp. 181-208. ISBN: 978-65-5630-012-2. https://doi.org/10.7476/9786556300122.0010. \section{International license.}

All the contents of this work, except where otherwise noted, is licensed under a Creative Commons Attribution 4.0

Todo o conteúdo deste trabalho, exceto quando houver ressalva, é publicado sob a licença Creative Commons Atribição 4.0. 


\section{Sintomas vocais e absenteísmo em teleoperadores sindicalizados}

Flávia Silva Santa Mônica Maria Lúcia Vaz Masson Tânia Maria de Araújo

\section{Introdução}

A voz vem sendo empregada, cada vez mais, como um importante instrumento de trabalho. Além dos profissionais mais tradicionais no uso da voz profissional (professores, atores e cantores), mudanças no mundo do trabalho nas últimas décadas têm feito surgir novas ocupações que utilizam a voz como principal ferramenta de trabalho. As várias modalidades de atendimento ao cliente no mercado competitivo das empresas configuram-se em uma dessas novas ocupações do mundo contemporâneo.

O avanço das tecnologias de telecomunicações ampliou as ferramentas de marketing criando, assim, uma nova categoria de trabalhadores: os teleoperadores ou teleatendentes. Estes profissionais atuam em centrais de teleatendimento, chamadas de call centers. Nesse contexto, a voz do teleoperador representa o elo entre consumidor e fornecedor.

Apesar do crescimento exponencial do teleatendimento com base em amplas possibilidades de seu uso no moderno mercado de trabalho, não se observou, na mesma velocidade, a incorporação de medidas de proteção aos trabalhadores. Assim, os processos de adoecimento têm sido frequentes nesse grupo, especialmente com relação aos agravos à saúde vocal. (JONES et al., 2002; LETHO et al., 2005; RECHENBERG, 2005; CEREST-SP, 2006; FERREIRA et al., 2008b; FERREIRA; SANTOS; LIMA, 2009; OLIVEIRA; BEHLAU; COUVEIA, 2009; CHRISTMANN et al., 2010; PIWOWARCZYK et al., 2010; RECHENBERG; 
GOULART; ROITHMANN, 2011; DASSIE-LEITE; LOURENÇO; BEHLAU, 2011). A ausência ao trabalho (absenteísmo) pode ser um indicativo importante dos processos de adoecimento em curso nesse grupo ocupacional.

Este capítulo busca descrever os agravos à saúde vocal, incluindo dados sobre absenteísmo, observados em teleoperadores que procuraram atendimento no Sindicato dos Trabalhadores em Telecomunicações da Bahia (SINTTEL-BA). Objetiva descrever a frequência de sintomas vocais, absenteísmo por problemas vocais e possíveis causas relacionadas à ausência ao trabalho, referidas por esses trabalhadores. Ademais, o estudo se propõe a refletir sobre os aspectos nocivos à saúde vocal, relacionados aos fatores ambientais e organizacionais do trabalho, que interferem na qualidade da saúde e da vida dos trabalhadores.

Além do estudo empírico, que permitirá avaliar uma situação concreta de trabalho em teleatendimento e os agravos vocais, serão também discutidos aspectos conceituais essenciais para a compreensão do campo de estudo apresentado. Desta forma, serão abordados aspectos relacionados ao setor de teleatendimento, à voz profissional, ao distúrbio de voz relacionado ao trabalho e ao absenteísmo por problemas de saúde.

\section{Serviços de teleatendimento/telemarketing}

Entende-se como trabalho de teleatendimento/telemarketing aquele cuja comunicação com interlocutores clientes e usuários é realizada à distância por intermédio da voz e/ou mensagens eletrônicas, com a utilização simultânea de equipamentos de audição/escuta e fala telefônica e sistemas informatizados ou manuais de processamento de dados. O call center é o principal ambiente de trabalho, no qual essa atividade é conduzida via telefone com utilização simultânea de terminais de computador. (BRASIL, 2007)

Segundo o Código Brasileiro de Ocupações, o profissional que lida diretamente com o cliente via teleatendimento é denominado "atendente", "operador de telemarketing" ou "teleoperador". Tais profissionais exercem as funções de atendimento ao cliente, oferecem serviços e produtos, prestam serviços técnicos especializados, realizam pesquisas e fazem serviços de cobrança e cadastramento. (BRASIL, 2012) 
De acordo com a Associação Brasileira de Telesserviços, no Brasil, o principal contratante de call center é o setor de serviços financeiros, seguido pelo de comércio varejista, telecomunicações, seguros, saúde e editoras/gráficas. Mais da metade dos centros de atendimento $(76 \%)$ foram implantados após o processo de privatização do setor de telecomunicações ocorrido em 1998, mostrando essa estratégia como elemento privilegiado na redução dos custos de implantação e manutenção das empresas em função, principalmente, da competitividade nesse setor. (OLIVEIRA JUNIOR, 2005)

O telemarketing - como canal de vendas, de atendimento ao consumidor ou de prestação de serviços - concretizou-se como a principal estratégia de muitas empresas, em várias situações e contextos de competição por mercados de consumidores. A consequência desse processo foi o crescimento geométrico dos profissionais dessa categoria de trabalhadores. (BEHLAU et al., 2005)

O trabalho em teleatendimento/telemarketing é dividido em duas modalidades principais: ativo e receptivo. Na modalidade ativa, a empresa toma a iniciativa de contato com o público, sendo utilizada majoritariamente para vendas. Já na modalidade receptiva, é o cliente quem entra em contato com a empresa, sendo o Serviço de Atendimento ao Consumidor (SAC) a aplicação mais conhecida.

As exigências no trabalho dos teleoperadores diferem com relação à modalidade de atendimento realizado. No telemarketing ativo há demanda de um profissional com segurança ao falar, com habilidade e capacidade de argumentação. Já na modalidade receptiva, o teleoperador deve ser gentil, paciente e ter capacidade de ouvir e interpretar as necessidades do cliente. (RATTO; ALBERMAZ; PELTIER, 2004) Segundo Algodoal e Alozza (2004), no ramo do telesserviço é indispensável ter como foco a voz, a fala, a linguagem e a audição numa relação de troca estabelecida pela comunicação. Portanto, a integração entre essas habilidades humanas, aliadas ao raciocínio rápido e à capacidade de previsão de comportamentos de outras pessoas, são exigências da profissão. Assim, essa não é uma atividade simples, de fácil execução como aparentemente parece ser. Exige rapidez de raciocínio, atenção, criatividade, habilidade comunicativa e paciência. Os processos de seleção, nesse caso, levam em conta o perfil vocal e comportamental que possam auxiliar na eficiência das ações de telemarketing. (BEHLAU; PONTES, 2005) 
As características dos processos de trabalho de teleatendimento assemelham-se às características do trabalho das telefonistas, acrescidas de elementos que intensificaram substantivamente o trabalho, especialmente o seu ritmo e cadência. (ARAÚJO, 2004) Com o uso de novas tecnologias e a informatização ampla do processo produtivo, por exemplo, os clientes são automaticamente direcionados ao atendimento, portanto o ritmo do trabalho é ditado pelos equipamentos, restringindo o controle do teleoperador sobre o seu próprio trabalho. Além disto, as demandas emocionais também cresceram significativamente nessa nova ocupação em função, sobretudo, do tipo de atendimento que deve ser oferecido: atender o cliente, seguir rigorosamente a rotina de procedimentos estabelecimentos pela empresa (muitas vezes ineficiente) e manter, em qualquer circunstância, a cordialidade e o mesmo tom de voz, mesmo frente às manifestações de insatisfação do cliente quando este não tem as suas demandas atendidas.

O trabalho em teleatendimento baseia-se em formas tradicionais de organização do trabalho centradas em relações de controle intenso do ritmo de trabalho (controle exercido pelos equipamentos e pela gerência), uso também intensivo das habilidades exigidas na atividade (no caso, o uso da voz), remuneração baseada na produtividade (alcance de metas) e supressão contínua de emoções geradas por situações de conflito e tensão na realização das tarefas diárias. (VILELA; ASSUNÇÃO, 2004; MOCELIN; SILVA, 2008)

\section{A voz profissional e distúrbio de voz relacionado ao trabalho}

A voz profissional é definida como uma forma de comunicação oral utilizada por indivíduos que dela dependem para exercer sua atividade ocupacional. (SBORL et al., 2004) Segundo Behlau e colaboradores (2005), o uso da voz em caráter profissional, sem o necessário preparo específico, pode sobrecarregar o aparelho fonador e gerar adaptações deficientes que se refletem numa disfonia/distúrbio.

As características da organização do trabalho (ritmo e jornada de trabalho, sistema hierárquico, nível de demandas laborais, controle sobre a atividade) e as condições do ambiente laboral (físicas, biológicas, 
químicas e ergonômicas) são elementos que também podem contribuir para os processos de agravos à saúde vocal. (ARAÚJO et al., 2008)

O Distúrbio de Voz Relacionado ao Trabalho (DVRT) é definido como qualquer alteração vocal que diminua, comprometa ou impeça a atuação e/ou a comunicação do trabalhador, diretamente relacionada ao uso da voz durante a atividade ocupacional; poderá ou não haver uma lesão orgânica da laringe. Geralmente o inicio dos sintomas é insidioso: predomina no final do dia, em função do uso excessivo da voz durante o trabalho e piora no decorrer dos dias. Com o descanso, a voz tende a melhorar. Contudo, no decorrer do tempo, os sintomas começam a se apresentar continuamente e sem expectativa de melhora. (BRASIL, 2012)

A disfonia relacionada ao trabalho manifesta-se por diversos sinais e sintomas que podem estar presentes concomitantemente ou não. Segundo pesquisas, os sinais e sintomas mais comuns relatados pelos teleoperadores são: garganta seca, cansaço para falar, pigarro, perda e falhas na voz, rouquidão, ardência e dor de garganta, tensão na região de pescoço, ombros e coluna. (FERREIRA et al., 2008b; CHRISTMANN et al., 2010; MORREIRA et al., 2010; PIWOWARCZYK et al., 2010; AMORIM et al., 2011; DASSIE-LEITE; LOURENÇO; BEHLAU, 2011) Dependendo da intensidade dos sintomas e do impacto destes na execução da atividade profissional, poderá haver a necessidade de afastamento e/ou ausência do trabalho.

O Distúrbio de Voz Relacionado ao Trabalho (DVRT) apresenta natureza multicausal e está associado a fatores ambientais e organizacionais do trabalho. Em geral, o teleoperador não dispõe de um ambiente ocupacional adequado ao desempenho de suas atividades profissionais, estando exposto a fatores de riscos ambientais (mudança brusca de temperatura, ambiente frio ou quente demais, presença de carpete, ar condicionado, poeira, fumaça e ruído) e fatores organizacionais desfavoráveis (uso intenso da voz, estresse relacionado ao trabalho, pausas insuficientes, relacionamento insatisfatório com chefia, colegas e clientes). (FERREIRA et al., 2008b)

Há também fatores relacionados às características individuais tais como idade, sexo feminino, uso vocal inapropriado ou excessivo, atividades extraprofissionais com alta demanda vocal, alergias respiratórias, doenças de vias aéreas superiores, influências hormonais, medicações, 
etilismo, tabagismo, falta de hidratação, estresse, refluxo gastroesofágico e outros que também estão relacionados aos agravos vocais. Os fatores de risco e predisponentes podem atuar de forma isolada e/ou combinada para o desenvolvimento do distúrbio vocal. (BRASIL, 2012)

No Brasil, a portaria GM/no 104/2011define as terminologias adotadas na legislação nacional sobre doenças, agravos e eventos em saúde pública de notificação compulsória em todo o território brasileiro. Esta portaria ainda não incluiu a disfonia relacionada ao trabalho entre os agravos de notificação compulsória no Sistema de Informação de Agravos de Notificação (SINAN). Uma tentativa de modificar essa realidade foi dada com a elaboração do Protocolo "Distúrbio de Voz Relacionado ao Trabalho" (DVRT), que foi posto em consulta pública, finalizada em abril de 2012, com vistas à inclusão da Disfonia na lista das doenças relacionadas ao trabalho a ser adotada nacionalmente.

Dados da literatura têm mostrado elevadas frequências de alterações vocais entre os profissionais da voz. (RECHENBERG, 2005; CEREST-SP., 2006; ARAÚJO et al., 2008; CEBALLOS et al., 2011) Desse modo, a notificação obrigatória desses agravos é de suma importância, pois permitirá o dimensionamento mais verdadeiro da situação atual e abrirá a possibilidade de detectar os fatores que interferem na produção vocal e no adoecimento, tornando viável o planejamento de ações de prevenção de distúrbios vocais e de promoção da saúde junto aos profissionais que utilizam a voz como instrumento de trabalho.

\section{Absenteísmo}

Absenteísmo é um conceito complexo. Neste estudo empregou-se a definição da Fundação Européia (1997) que define como incapacidade temporária, prolongada ou permanente para trabalhar, devido a problemas de saúde. Tornou-se um dos assuntos mais polêmicos e preocupantes na área de call center que, estatisticamente, é um setor com índice elevado de absenteísmo no Brasil. (ZAMBON, 2009)

O absenteísmo configura-se como alvo constante de atenções e preocupações por parte dos empresários, executivos e médicos do trabalho. Para os empresários, porque influi negativamente no balanço econômico, podendo representar perdas significativas na produtividade esperada. Para os profissionais da saúde, é objeto de avaliação e 
análise, considerando que é tarefa dos serviços de saúde ocupacional e de medicina do trabalho conhecer a situação de saúde dos trabalhadores, acompanhar sua evolução e identificar os fatores que podem estar contribuindo para as ocorrências de falta ao trabalho, de modo a permitir a elaboração de medidas de prevenção e promoção da saúde nos ambientes de trabalho. (MARQUES NETO, 2006)

Quick e Lapertosa (1982) dividem o absenteísmo em cinco tipos: a) absenteísmo voluntário (devido a razões particulares não justificadas por doença); b) absenteísmo por doença (ausências por doenças ou procedimentos médicos, excetuando-se os infortúnios profissionais); c) absenteísmo por patologia profissional (devido a acidentes de trabalho ou doença profissional); d) absenteísmo legal (faltas ao serviço amparadas por leis, como: gestação, motivos particulares, doação de sangue e serviço militar); e) e absenteísmo compulsório (impedimento ao trabalho devido à suspensão imposta pelo patrão, por prisão ou outro impedimento que não permita o trabalhador chegar ao local de trabalho).

As principais causas do absenteísmo nos call centers são doenças, direitos legais (doação de sangue, participação em júris ou eleições, licença maternidade, entre outros), fatores sociais (doença de familiares, dificuldades com transportes) e desmotivação.

No call center, o absenteísmo é um indicador de qualidade dos serviços prestados. As ausências dos funcionários provocam alterações importantes no fluxo de atendimento. Como existe um dimensionamento do número de funcionários necessários para atender certa demanda de chamadas, a ausência do teleoperador modifica o planejamento do trabalho, bem como o número de chamadas a serem atendidas em um dado período de tempo. Quando o funcionário se ausenta do trabalho, gera atraso no tempo de espera para o cliente ser atendido, pois a empresa teve redução na sua força de trabalho, o que gera insatisfação do cliente, consequentemente, redução dos indicadores de qualidade do atendimento. (ZAMBON, 2009)

Portanto, as constantes faltas dos trabalhadores podem ajudar na identificação de possíveis problemas estruturais na empresa, servindo como alerta de que algo na organização e no ambiente ocupacional não vai bem. Em relação ao absenteísmo e à disfonia em teleoperadores, provavelmente a presença de um quadro disfônico parece culminar em 
absenteísmo e/ou afastamento do trabalho, pelo fato da voz ser a principal ferramenta utilizada.

A existência de inúmeros sintomas vocais em teleoperadores e o elevado absenteísmo nessa categoria profissional motivaram a realização deste estudo. Optou-se por realizá-lo no Sindicato dos Trabalhadores em Telecomunicações da Bahia (SINTTEL-BA), devido à resistência por parte das empresas da cidade do Salvador quanto à disponibilidade de acesso para aplicação de questionário relacionado à saúde no ambiente ocupacional.

\section{Materiais e metodos}

Realizou-se um estudo epidemiológico de corte transversal, com caráter descritivo. Utilizou-se uma amostra de conveniência composta por 80 teleoperadores que buscaram atendimento no Sindicato dos Trabalhadores em Telecomunicações da Bahia (SINTTEL-BA), no período de julho a outubro de 2010. Foram incluídos operadores de telemarketing ativo e receptivo, sem restrição de faixa etária e de ambos os sexos. Os trabalhadores procuram o sindicato para os serviços de homologação da rescisão de contrato de trabalho, atendimento médico ou jurídico e busca de informações. Cada teleoperador, que compareceu ao sindicato e aceitou participar do estudo, foi entrevistado. A coleta de dados foi realizada durante o horário de funcionamento do sindicato nos turnos da manhã e/ou tarde, de segunda a sexta-feira, em dias alternados. Portanto, o critério de inclusão foi ter procurado o sindicato e aceitar participar do estudo.

\section{Instrumento de pesquisa}

Foi utilizado um questionário adaptado de Ferreira e colaboradores (2008b), sendo acrescidas perguntas referentes ao absenteísmo. O instrumento contém 21 questões, sendo parte delas avaliada aqui, a saber: dados sociodemográficos e funcionais, sintomas vocais presentes nas últimas duas semanas, causas desses sintomas na percepção do teleoperador e absenteísmo. As características sociodemográficas e do trabalho estudadas foram: sexo, idade, tempo de profissão, carga horária semanal, modalidade de atendimento (ativo, receptivo e híbrido), setor 
de atendimento (televendas, atendimento ao cliente, help desk, cobrança, suporte técnico, retenção e pesquisa).

A aplicação do questionário foi realizada pela primeira autora do estudo. Os sujeitos foram abordados na sala de espera do SINTTEL-BA e convidados a participar da pesquisa. Os que se dispuseram voluntariamente a participar assinaram o termo de consentimento livre e esclarecido e responderam ao instrumento.

\section{Variáveis de estudo}

Nesta pesquisa, conforme estabelecido nos objetivos, foram investigados os sintomas vocais, absenteísmo e possíveis causas relacionadas à ausência ao trabalho.

Para analisar a frequência de sintomas vocais foi solicitado ao teleoperador que respondesse à questão "sintomas vocais presentes nas duas últimas semanas". A partir de uma lista de sintomas previamente elaborada que incluíram: cansaço ao falar, ardor na garganta, falhas na voz, rouquidão, perda da voz, pigarro, esforço ao falar, garganta e/ou boca seca, voz mais grossa, voz mais fina, voz fraca, voz forte, voz pior pela manha e voz pior pela noite. O teleoperador respondia os sintomas ocorridos nas últimas duas semanas.

Possíveis causas ocupacionais dos sintomas referidos foram avaliadas com base na questão "em sua opinião, esse sintoma acontece por quê?" As respostas foram estruturadas da seguinte forma: uso intenso da voz, presença de carpete no ambiente de trabalho, mobiliário inadequado, presença de ar condicionado, presença de ruído no ambiente, presença de ruído ao headset, ambiente frio ou quente demais, mudança brusca de temperatura, presença de poeira, presença de produto de limpeza com cheiro forte, presença de fumaça, estresse relacionado ao trabalho, falta de intervalos para descanso e relacionamento insatisfatório com a chefia, colegas ou clientes.

O absenteísmo foi analisado com base na questão "nos últimos seis meses você faltou trabalho por problemas de voz?", sendo aceita apenas uma resposta com escala dicotômica ( $\operatorname{sim} /$ não). 


\section{Análise dos dados}

Os resultados foram digitados em planilha específica e analisados descritivamente com auxílio do programa SPSS (Statistical Package for Social Sciences), versão 17.0 para Windows.

A análise descritiva dos dados incluiu a descrição da população estudada e das variáveis de interesse já mencionadas. Os dados sociodemográficos foram calculados em médias de: idade, tempo de serviço e carga horária semanal. Para definição do serviço procurado no Sindicato as respostas, inicialmente abertas, foram categorizadas nos seguintes serviços: atendimento médico, atendimento jurídico, homologação e informações. As frequências dos sintomas vocais e das possíveis causas dos sintomas referidas foram descritas em número e percentual. A frequência de absenteísmo por problemas vocais foi estimada da mesma maneira (número e percentual). Para a definição do problema vocal que provocou o absenteísmo, consideraram-se as respostas abertas dos trabalhadores que faltaram ao trabalho, as quais foram posteriormente categorizadas em rouquidão, perda da voz, dor de garganta, inflamação de garganta e problemas múltiplos, quando referiam mais de um motivo (rouquidão + perda de voz, rouquidão + inflamação da garganta, rouquidão + perda de voz + dor). Para o atendimento de saúde procurado devido ao absenteísmo, foi estimada a frequência de categorias profissionais previamente estabelecidas (médico otorrinolaringologista, médico do trabalho, fonoaudiólogo e outros).

O tempo de afastamento do trabalho foi calculado segundo número de faltas em dias consecutivos, considerando as opções: um dia, dois dias, sete dias, 15 dias e uma alternativa aberta para responder ao número de dias faltosos que não se enquadrava nas faixas descritas.

Analisou-se também se houve necessidade de afastamento em função desse problema em resposta dicotômica ( $\operatorname{sim} /$ não) e se o trabalhador procurou atendimento especializado (fonoaudiologia e otorrinolaringologia) por causa do problema de voz.

\section{Aspectos éticos}

O projeto de pesquisa foi aprovado pelo Comitê de Ética em Pesquisa da Escola Bahiana de Medicina e Saúde Pública (protocolo 
$n^{\circ}$ 065/2010). A direção do SINTTEL-BA autorizou a coleta dos dados. Os trabalhadores entrevistados assinaram o termo de consentimento livre e esclarecido, conforme descrito anteriormente, em acordo com a Resolução no. 196/96.

\section{Resultados e discussão}

A amostra contou com a participação de 80 teleoperadores, sendo $20 \%$ do sexo masculino e $80 \%$ do feminino, com média de idade de 28 anos; idade mínima de 19 anos e máxima de 52 anos. O serviço do Sindicato mais procurado pelos teleoperadores foi o de homologação $(68,8 \%)$, seguido do serviço médico $(26,3 \%)$ e de outros serviços que somaram $5 \%$.

A presença majoritária de mulheres no ramo do telesserviço é corroborada por outros estudos. (MOCELIN; SILVA, 2008; CHRISTMANN et al., 2010; MORREIRA et al., 2010; PIWOWARCZYK et al., 2010; AMORIM et al., 2011; DASSIE-LEITE; LOURENÇO; BEHLAU, 2011; RECHENBERG; GOULART; ROITHMANN, 2011) O call center no Brasil apresenta $76,2 \%$ de participação do sexo feminino em sua força de trabalho e $23,8 \%$ de homens. (OLIVEIRA JUNIOR, 2005) A amostra aqui estudada é compatível, portanto, com o perfil encontrado no setor de telemarketing como um todo.

Esse predomínio de participação feminina nesse setor decorre da busca de espaço no mercado de trabalho pelas mulheres, por um lado, e, por outro, pelas características dos postos de trabalho nesse setor (em geral, marcado por formas autoritárias de gestão do trabalho, com restrição de tempo, modos rígidos de execução das tarefas e vínculos empregatícios precários), reunindo características dos postos de trabalho comumente designados às mulheres na divisão sexual do trabalho no capitalismo. (ARAÚJO et al., 2006) Em estudo sobre o panorama da situação das mulheres no mercado de trabalho no Brasil, Bruschini (2007) pontua crescimento intenso e constante da participação feminina no mercado de trabalho, mas destaca que ainda há uma tendência de inserção das mulheres em empregos de má qualidade com predomínio em atividades precárias e informais. Destaca ainda, nesse perfil, uma tendência mais recente de acesso a carreiras e profissões de prestígio e a cargos de gerência e diretoria, por parte de mulheres escolarizadas - 
movimento ainda restrito em função das dificuldades de acesso escolar, de modo geral, no país.

Ressalta-se, também, o turno de trabalho (carga horária de seis horas diárias), permitindo que as mulheres possam conciliar a atividade laboral com as atividades exercidas na família, como o cuidado da casa e dos filhos. A literatura aponta que, para as mulheres, a conciliação do trabalho remunerado e doméstico tem significado a opção por postos de trabalho de tempo parcial. (BRUSCHINI, 2007)

Em relação à situação funcional, os trabalhadores referiram atuar no setor, em média, há 38 meses (pouco mais de três anos na atividade), com carga horária média de 36 horas semanais. O turno dos teleoperadores é de seis horas diárias, com 15 minutos de intervalo.

Sobre a faixa etária, a maioria dos teleoperadores estava entre 20 a 24 anos $(42,6 \%)$ e entre 25 a $29(30,7 \%)$, representando $73,3 \%$ do total. A possibilidade de um emprego de meio período atrai jovens profissionais que, muitas vezes, possuem duas profissões ou jornada dupla de trabalho. (BEHLAU et al., 2005) A predominância de adultos jovens também foi encontrada em outras pesquisas. (FERREIRA et al., 2008b; MOCELIN; SILVA, 2008; MORREIRA et al., 2010; AMORIM et al., 2011; DASSIE-LEITE ; LOURENÇO; BEHLAU, 2011) As empresas de call center empregam, na sua grande maioria, jovens vivenciando o primeiro emprego que não têm a pretensão de seguir carreira no ramo. O teleatendimento é encarado como uma atividade temporária, com alta rotatividade de trabalhadores, o que implica no fato de não haver envelhecimento dos empregados, pois há uma forte tendência a deixar o emprego quando se atinge uma determinada faixa etária, que parece coincidir com a conclusão da formação educacional. (VILELA; ASSUNÇÃO, 2004; MOCELIN; SILVA, 2008) Provavelmente, devido a esses fatores, o serviço mais procurado pelos sujeitos desta pesquisa tenha sido o de homologação, visando à formalização do término do vínculo trabalhista.

A maioria dos entrevistados atuava no setor de atendimento ao cliente $(56,3 \%)$, seguido pelos setores de televendas $(28,8 \%)$, suporte técnico $(2,5 \%)$ e retenção $(1,3 \%)$. Parte dos teleoperadores atuava em mais de um setor (10\%). Segundo a distribuição por modalidade de teleatendimento, $70 \%$ dos teleoperadores entrevistados estavam na função exclusivamente receptiva, $15 \%$ atuavam na função híbrida e o mesmo 
percentual em função exclusivamente ativa. Esses achados são consistentes com os de outros estudos. (FERREIRA et al., 2008b; MOCELIN; SILVA, 2008; RECHENBERG, 2005) O atendimento receptivo mostra-se mais prejudicial, particularmente à voz, pois esta modalidade, quando comparada ao atendimento ativo, é marcada pelo grande fluxo de ligações e inexistência de pausas entre os atendimentos, havendo maior exigência vocal. As demandas emocionais do trabalho também são intensificadas neste tipo de atendimento - o que pode elevar ainda mais o estresse ocupacional, já gerado pela demanda excessiva e o baixo controle sobre o trabalho. O atendimento ativo também promoveria desgaste da voz, mas em grau menor. (GUENA, 2009)

Todos os teleoperadores entrevistados referiram, pelo menos, um tipo de sintoma vocal. Os sintomas vocais mais referidos nas duas últimas semanas foram: garganta e/ou boca seca $(41,3 \%)$, ardor na garganta e falhas na voz (ambos com 33,8\%), rouquidão e pigarro (31,3\% para ambos) (Tabela 1). Estes achados corroboram estudos de outros autores. (FERREIRA et al., 2008b; PIWOWARCZYK et al., 2010; DASSIE-LEITE; LOURENÇO; BEHLAU, 2011; AMORIM et al., 2011; RECHENBERG; GOULART; ROITHMANN, 2011) 
Tabela 1 - Distribuição de sintomas vocais presentes nas duas últimas semanas referidas por teleoperadores $(\mathrm{N}=80)$. Salvador, 2010.

\begin{tabular}{|c|c|c|}
\hline Sintomas & $\mathbf{n}$ & $(\%)$ \\
\hline Garganta/boca seca & 33 & 41,3 \\
\hline Ardor na garganta & 27 & 33,8 \\
\hline Falhas na voz & 27 & 33,8 \\
\hline Rouquidão & 25 & 31,3 \\
\hline Pigarro & 25 & 31,3 \\
\hline Cansaço ao falar & 21 & 26,3 \\
\hline Voz mais grossa & 10 & 12,5 \\
\hline Voz fraca & 09 & 11,3 \\
\hline Voz pior pela manhã & 09 & 11,3 \\
\hline Voz pior pela noite & 07 & 8,8 \\
\hline Perda da voz & 07 & 8,8 \\
\hline Esforço ao falar & 07 & 8,8 \\
\hline Voz mais fina & 05 & 6,3 \\
\hline Voz forte & 01 & 1,3 \\
\hline
\end{tabular}

Fonte: (MÔNICA; MASSON; ARAÚJO, 2010)

As prováveis causas dos sintomas vocais referidos mais citadas foram: uso intenso da voz $(70,0 \%)$, estresse relacionado ao trabalho $(46,4 \%)$ e circunstâncias decorrentes de condições do ambiente de trabalho como presença de ar condicionado $(57,5 \%)$ e ambiente frio ou quente demais $(35,5 \%)$ (Tabela 2$)$.

Dentre os hábitos relacionados à voz que eram realizados imediatamente antes ou durante o trabalho destacaram-se: ingerir gelado ou tomar café (ambos com 45,0\%) falar muito (41,3\%) e ingerir chocolate $(36,3 \%)$. Tais hábitos são prejudiciais à voz e deveriam ser evitados durante o período de atuação profissional. Os gelados provocam descarga de muco nas pregas vocais, como um sistema de defesa contra o choque térmico da mudança de temperatura. O consumo de café pode favorecer o refluxo gastresofágico, que é extremamente irritante para a sensível mucosa da laringe. (BEHLAU; PONTES, 1995, BEHLAU et al., 2001) A situação piora ainda mais, considerando-se as condições de trabalho em que os teleoperadores geralmente estão submetidos, com 
intenso uso da voz, pausas restritas e dificuldade de acesso a alimentos saudáveis.

Tabela 2 - Distribuição das possíveis causas para os sintomas vocais referidas pelos teleoperadores $(\mathrm{N}=80)$. Salvador, 2010

\begin{tabular}{l|c|c}
\multicolumn{1}{c|}{ Causas referidas } & n & (\%) \\
\hline Uso intenso da voz & 56 & 70,0 \\
\hline Presença de ar condicionado & 46 & 57,5 \\
\hline Estresse no trabalho & 37 & 46,3 \\
\hline Ambiente frio ou quente demais & 30 & 37,5 \\
\hline Presença de poeira & 27 & 33,8 \\
\hline Mudança brusca de temperatura & 19 & 23,8 \\
\hline Presença de ruído ao telefone (headset) & 16 & 20,0 \\
\hline Mobiliário inadequado & 11 & 13,8 \\
\hline Maior número de intervalos para descanso & 10 & 12,5 \\
\hline Presença de ruído no ambiente & 10 & 12,5 \\
\hline Relacionamento insatisfatório com chefia, colegas e clientes & 09 & 11,3 \\
\hline Presença de carpete no ambiente de trabalho & 08 & 10,0 \\
\hline Presença de produto de limpeza com cheiro forte & 04 & 5,0 \\
\hline
\end{tabular}

Fonte: (MÔNICA; MASSON; ARAÚJO, 2010)

A análise da situação de saúde dos teleoperadores incluiu avaliação de problemas de saúde relativos às vias aéreas, ao aparelho auditivo e morbidade em geral (Tabela 3 ). Com relação às vias aéreas destacaram-se as rinites $(36,3 \%)$ e as sinusites $(23,8 \%)$. Coceira no ouvido $(30,0 \%)$, dificuldade de ouvir e zumbido (ambos com 22,5\%) foram os problemas do aparelho auditivo mais frequentemente relatados. Quando se avaliou a saúde em geral, os teleoperadores relataram, em maior frequência, problemas de coluna $(37,5 \%)$, problemas emocionais $(32,5 \%)$, distúrbios do sono $(31,3 \%)$ e problemas digestivos $(21,3 \%)$. 
Tabela 3 - Distribuição de problemas em vias aéreas, no aparelho auditivo e de saúde geral, referidos pelos teleoperadores $(\mathrm{N}=80)$. Salvador, 2010

\begin{tabular}{|c|c|c|}
\hline Problemas de Saúde & $\mathbf{n}$ & $(\%)$ \\
\hline \multicolumn{3}{|c|}{ Vias aéreas } \\
\hline Rinite & 29 & 36,3 \\
\hline Sinusite & 19 & 23,8 \\
\hline Amigdalite & 08 & 10,0 \\
\hline Faringite & 04 & 5,0 \\
\hline Laringite & 03 & 3,8 \\
\hline Asma & 02 & 2,5 \\
\hline Bronquite & 01 & 1,3 \\
\hline \multicolumn{3}{|c|}{ Aparelho auditivo } \\
\hline Coceira no ouvido & 24 & 30,0 \\
\hline Intolerância a sons & 19 & 23,8 \\
\hline Zumbido & 18 & 22,5 \\
\hline Dificuldade de ouvir & 18 & 22,5 \\
\hline Intolerância a sons & 19 & 23,8 \\
\hline Dor no ouvido & 16 & 20,0 \\
\hline \multicolumn{3}{|c|}{ Saúde Geral } \\
\hline Problemas de Coluna & 30 & 37,5 \\
\hline Problemas emocionais & 26 & 32,5 \\
\hline Distúrbios do sono & 25 & 31,3 \\
\hline Problemas digestivos & 17 & 21,3 \\
\hline Problemas circulatórios & 16 & 20,0 \\
\hline Problemas psiquiátricos & 12 & 15,0 \\
\hline Problemas neurológicos & 12 & 15,0 \\
\hline LER/DORT & 09 & 11,3 \\
\hline Problemas hormonais & 06 & 7,5 \\
\hline
\end{tabular}

Fonte: (MÔNICA; MASSON; ARAÚJO, 2010)

A morbidade referida pelos teleoperadores foi compatível com as exigências do trabalho e coerentes com estudos junto a essa população. (FERREIRA et al., 2008b; CHRISTMANN et al., 2010; PIWOWARCZYK et al., 2010; MOREIRA et al., 2010; DASSIE-LEITE; LOURENÇO; BEHLAU, 2011; AMORIM et al., 2011; RECHENBERG; GOULART; ROITHMANN, 2011) Queixas de coceira no ouvido, dificuldade de 
ouvir e zumbido estão relacionadas às demandas excessivas sobre o aparelho auditivo. O uso contínuo de aparelhos como headsets por jornada de trabalho de seis horas (com apenas 15 minutos de descanso) pode representar exposição importante para as queixas referidas. A queixa de problema de coluna foi a mais relevante, estando, provavelmente, associada à postura sentada mantida durante a atividade laboral. Por fim, os sintomas psicossomáticos também tiveram destaque: os problemas emocionais, distúrbios do sono e problemas digestivos podem ser indicativos de vivência constante de situações envolvendo elevado nível de estresse ocupacional.

No ambiente do call center são necessários equipamentos de ar condicionado, pela presença dos computadores em funcionamento. Alguns indivíduos são muitos sensíveis ao ar condicionado, isto porque o resfriamento do ar realizado através da retirada de umidade do meio ambiente, resseca a mucosa do trato vocal. A movimentação da mucosa fica comprometida devido à diminuição da lubrificação laríngea em decorrência da presença do ar condicionado. (BEHLAU; PONTES, 1995) A queixa de garganta seca, relatada por significativo percentual dos teleoperadores, pode ser em função da combinação entre exposição ao ar condicionado e abertura frequente da cavidade oral pelo uso contínuo da voz. (RECHENBERG, 2005)

Os teleoperadores, por trabalharem em ambiente com baixa temperatura, enfrentam mudanças bruscas de temperaturas e, por não terem o hábito de hidratação oral, apresentam problemas de falta de lubrificação e/ou hidratação laríngea. (BEHLAU et al., 2005) Vale ressaltar que tal hábito é imposto pela organização do trabalho, que dificulta a ingestão de líquidos. No estudo de Rocha e colaboradores (2006) foi evidenciado que o aumento da ingestão de água representava a necessidade dos trabalhadores de ir ao banheiro com maior frequência, o que era um problema diante da dificuldade dos teleoperadores afastarem-se do posto de trabalho durante os horários de pico das ligações.

Estudos evidenciam relação estatisticamente significante entre as afecções respiratórias altas e o sintoma de ardor na garganta. (FERREIRA; SANTOS; LIMA, 2009) As afecções respiratórias afetam a hidratação do trato vocal, causam ressecamento na faringe e, consequentemente, irritação na garganta. No geral, há um ressecamento do 
trato vocal por conta da respiração oral, fato que acarreta uma sensação de ardor na garganta. (BEHLAU et al., 2001)

Segundo Behlau e Pontes (1995), a voz rouca é a manifestação mais comum de alteração vocal. Esse tipo de voz geralmente está relacionado a lesões orgânicas na laringe, representando uma alteração na vibração das pregas vocais. Queixas como rouquidão, falhas na voz e cansaço vocal, podem ser decorrentes do uso prolongado da voz durante a jornada de trabalho, sendo indicativo de sobrecarga vocal. (JONES et al., 2002; LETHO et al., 2005) Para Amorim e colaboradores (2011), tais sintomas podem sugerir um quadro inicial de disfonia, gerando riscos elevados para a função vocal em virtude da permanência nas atividades profissionais, mesmo diante de desconforto fonatório. Os achados deste estudo reforçam a hipótese de que há uma estreita relação entre a presença da rouquidão e o uso abusivo da voz, como tem sido observado em vários estudos na literatura. (ARAÚJO et al., 2008)

Um sintoma presente nos quadros gripais é o pigarro, cuja finalidade é expelir a secreção que se acumula nas pregas vocais. Contudo, o hábito de realizá-lo com frequência, independentemente desses quadros, confere atrito constante, causando aumento na produção de muco como estratégia de defesa deste impacto. Esse ciclo vicioso compromete a emissão vocal, forçando um novo ato de pigarrear. (PINHO, 1997)

Segundo Behlau e colaboradores (2005), o pigarro também pode ser consequência do ressecamento provocado pela refrigeração do ambiente, como ocorre nas centrais de teleatendimento. A falta de manutenção no ar condicionado geralmente aumenta a incidência de doenças respiratórias.

A literatura alerta para uma série de alterações que podem influenciar o estabelecimento do quadro disfônico, as quais podem contribuir para sua manutenção e recorrências. As principais dizem respeito aos distúrbios alérgicos, faríngeos, bucais, nasais, otológicos, pulmonares, digestivos, hormonais e neurovegetativos. Os distúrbios nasais e alérgicos - rinite e sinusite - foram os mais referidos. Estes alteram a ressonância e podem modificar o padrão vibratório da laringe, induzindo a uma contração na produção dos sons. Alguns indivíduos referem o início de sua disfonia em decorrência de abuso vocal em situações de quadro alérgico ou gripal. (BEHLAU; PONTES, 1995) 
Estudo concluiu que os teleoperadores tinham duas vezes mais chances de apresentar um ou mais sintomas vocais, principalmente se fossem mulher, sedentárias, fumantes, e se tivessem problemas nasais, ou exposição a ambiente frio. (JONES et al. 2002)

O ambiente físico das centrais de telemarketing e a própria função de teleoperador podem agir como estressores ou potencializadores de estresse, pois o cotidiano do teleoperador está marcado por situações que geram reações de irritação, ansiedade e até medo e confusão. Também, a própria situação de uma possível dificuldade de comunicação, passa a ser um agente estressor. (MONTORO, 1998) Como exemplos estão: o fato de ter que lidar com o controle de tempo das ligações, a manutenção do script, o monitoramento de atrasos, pausas e ausências por meio de pontuações, a produtividade e a cobrança por resultados. (VILELA; ASSUNÇÃO, 2004) Os teleoperadores referem que a postura permanente durante seis horas diárias, o toque constante do sinal telefônico, o uso do fone de ouvido e instabilidade no emprego são aspectos geradores do estresse. (FERREIRA et al., 2008a) O estresse ocupacional tem sido associado a diversos processos de adoecimento físico e mental em diferentes grupos ocupacionais. (ARAÚJO; CERQUEIRA; ARAÚJO, 2003)

Para avaliar a relação entre sintomas vocais e aspectos laborais, analisaram-se os três sintomas mais relevantes (garganta e/ou boca seca, falha na voz e rouquidão) (Tabela 4). Para esses sintomas investigados, a frequência foi mais elevada entre aqueles que referiram condições de trabalho desfavoráveis. As diferenças mais marcantes foram observadas quando o teleoperador referiu uso intenso da voz: a ocorrência do sintoma, quando essa condição estava presente, foi 10 vezes maior para rouquidão $(44,6 \%$ contra $5,2 \%) ; 5,2$ vezes maior para falhas na voz (43,5\% contra $8,3 \%)$; e 4,1 vezes maior para garganta/boca seca $(51,7 \%$ contra $12,5 \%)$ (Tabela 4$)$. Merece destaque também a presença de estresse ocupacional que aumentou 2,4 vezes mais a frequência de garganta/boca seca; 1,5 vezes a frequência de falhas na voz; e 1,4 vezes a rouquidão. 
Tabela 4 - Frequência (\%) de sintomas vocais segundo presença (sim) e ausência (não) das condições de trabalho referidas nos teleoperadores $(N=80)$. Salvador, 2010

\begin{tabular}{|c|c|c|c|c|c|c|}
\hline \multirow{2}{*}{$\begin{array}{l}\text { Características e condições do } \\
\text { trabalho referidas }\end{array}$} & \multicolumn{2}{|c|}{$\begin{array}{l}\text { Garganta/ } \\
\text { Boca seca }\end{array}$} & \multicolumn{2}{|c|}{ Falhas na voz } & \multicolumn{2}{|c|}{ Rouquidão } \\
\hline & Sim & Não & Sim & Não & Sim & Não \\
\hline Uso intenso da voz & 51,7 & 12,5 & 42,9 & 8,3 & 44,6 & 4,2 \\
\hline Presença de ar condicionado & 50,0 & 20,6 & 43,5 & 17,6 & 32,6 & 23,5 \\
\hline Estresse no trabalho & 45,9 & 16,3 & 51,4 & 20,9 & 37,8 & 25,6 \\
\hline Ambiente frio ou quente demais & 56,7 & 30,0 & 46,7 & 26,0 & 33,0 & 30,0 \\
\hline Presença de poeira & 59,2 & 32,0 & 51,9 & 20,8 & 33,3 & 30,2 \\
\hline Mudança brusca de temperatura & 68,4 & 32,8 & 36,8 & 32,8 & 42,1 & 27,9 \\
\hline Presença de ruído ao telefone (headset) & 68,8 & 34,4 & 56,3 & 28,1 & 50,0 & 26,6 \\
\hline Mobiliário inadequado & 63,6 & 37,7 & 54,5 & 29,0 & 54,5 & 27,5 \\
\hline Maior número de intervalos para descanso & 38,6 & 30,0 & 30,0 & 60,0 & 50,0 & 28,6 \\
\hline Presença de ruído no ambiente & 40,0 & 40,0 & 50,0 & 31,4 & 50,0 & 28,6 \\
\hline $\begin{array}{l}\text { Relacionamento insatisfatório com chefia, } \\
\text { colegas e clientes }\end{array}$ & 44,4 & 40,8 & 44,4 & 31,0 & 44,4 & 32,4 \\
\hline
\end{tabular}

Fonte: (MÔNICA; MASSON; ARAÚJO, 2010)

Com relação ao absenteísmo, 35\% dos teleoperadores $(\mathrm{n}=28)$ faltaram ao trabalho nos últimos seis meses por problemas na voz. As faixas de dias faltosos mais frequentes foram dois dias, $(35,7 \%)$; três dias $(28,6 \%)$; e um dia $(10,7 \%)$.

Quando perguntados sobre qual foi o problema vocal que os impossibilitou comparecer ao exercício de sua função, a maioria relatou sintoma único de rouquidão $(46,4 \%)$, seguido por problemas múltiplos (rouquidão e perda da voz ou rouquidão e inflamação da garganta, 21,4\%) (Tabela 5). 
Tabela 5 - Distribuição dos teleoperadores que faltaram ao serviço ${ }^{1}(\mathrm{n}=28)$ segundo tipo de problema de voz referido, atendimentos procurados e exigência/ condições de trabalho referidos como causa do afastamento. Salvador, 2010

\begin{tabular}{l|c|c}
\multicolumn{1}{c|}{ VARIÁVEIS } & $\mathrm{n}$ & $(\%)$ \\
\hline Problemas vocais referidos (N=28) & & \\
\hline Rouquidão & 13 & 46,4 \\
\hline Inflamação na garganta & 05 & 17,9 \\
\hline Perda da voz & 03 & 10,7 \\
\hline Dor de garganta & 01 & 3,6 \\
\hline Múltiplos ${ }^{17}$ & 06 & 21,4 \\
\hline Atendimentos procurados (N=28) & & \\
\hline Médico ORL & 16 & 57,1 \\
\hline Fonoaudiólogo & 02 & 7,2 \\
\hline Médico do trabalho & 01 & 3,6 \\
\hline Outros ${ }^{18}$ & 06 & 21,4 \\
\hline Não informaram & 03 & 10,7 \\
\hline Fatores associados ao afastamento referidos como causa (n=28) & $\mathrm{n}$ & $\%$ \\
\hline Uso intenso da voz & 18 & 64,7 \\
\hline Ambiente frio ou quente demais & 13 & 46,4 \\
\hline Presença de ar condicionado & 12 & 42,9 \\
\hline Estresse no trabalho & 10 & 35,7 \\
\hline Presença de poeira & 08 & 28,6 \\
\hline Mudança brusca de temperatura & 06 & 21,4 \\
\hline Presença de ruído ao telefone (headset) & 05 & 18,9 \\
\hline Mobiliário inadequado & 04 & 14,3 \\
\hline Presença de ruído no ambiente & 02 & 14,3 \\
\hline Relacionamento insatisfatório com chefia, colegas e clientes & 7,1 \\
\hline
\end{tabular}

Fonte: (MÔNICA; MASSON; ARAÚJO, 2010)

As taxas de absenteísmo mostraram-se similares (29\%) às encontradas por Reichenberg, Goulart e Roithmann (2011) e maiores nos teleoperadores quando comparadas às dos professores Smith e

1 A análise do número de dias ausentes evidenciou que as faixas de dias faltosos mais frequentes foram dois dias $(35,7 \%)$; três dias $(28,6 \%)$ e um dia $(10,7 \%)$.

2 Mais de um problema referido, a saber: rouquidão + perda de voz, rouquidão + inflamação da garganta, rouquidão + perda de voz + dor.

3 Emergência, atendimento clínico e ortopédico. 
colaboradores (1998), Simberg, Sala e Ronnemaa (2004), 20\% e 18\%, respectivamente. Tal situação parece reforçar a percepção de que, na vigência de uma disfonia, o trabalho torna-se inviável entre teleoperadores, uma vez que a voz é condição sine qua non de trabalho. Para os professores, a presença da disfonia, em estágio inicial, não parece tão crítica a ponto de gerar taxas de absenteísmo muito elevadas, dada a possibilidade de utilizar outros recursos pedagógicos que viabilizavam a continuidade do trabalho. (RECHENBERG; GOULART; ROITHMANN, 2011)

Um maior nível de controle sobre as atividades laborais cotidianas possibilita uso de outros recursos para poupar a voz nesses momentos. No entanto, cabe mencionar que esse recurso, aparentemente benéfico entre professores, não raro, disfarça a relevância do sintoma, contribuindo para o seu agravamento e cronificação. (ARAÚJO et al., 2008)

Com relação à procura de atendimento na área da saúde frente ao problema vocal apresentado, a maioria dos teleoperadores afirmou procurar um otorrinolaringologista $(57,1 \%)$; um pequeno percentual que buscou o fonoaudiólogo $(7,2 \%)$ e o médico do trabalho do sindicato $(3,6 \%)$ (Tabela 3$)$. Outras especialidades como emergência e clínica médica foram também procuradas pelos entrevistados (21,4\%) (Tabela 5).

Entre os teleoperadores que se afastaram do trabalho, o período de tempo de afastamento mais frequente foi de dois $(35,7 \%)$ e de três dias $(28,6 \%)$. A alta frequência de procura por serviços de saúde evidenciou que o trabalhador vislumbrava uma solução, ainda que imediata, para os seus problemas de voz. O fato da maior procura ser pelo otorrinolaringologista pode estar relacionado a uma busca de alívio de sintomas. Como a disfonia relacionada ao trabalho ainda não é reconhecida como doença ocupacional, há um limite jurídico para o estabelecimento do nexo causal da doença, sendo que as possibilidades de afastamento do trabalho ficam restritas a renovações sistemáticas de atestados por doenças comuns.

Estudos têm demonstrado claramente os resultados benéficos das intervenções fonoaudiológica em teleoperadores, como realização de oficinas para melhorias nos padrões do perfil vocal, principalmente nas mulheres. Após a realização de um curto treinamento de dois dias houve relatos de diminuição da fadiga vocal, da sensação de muco, do 
pigarro ao longo do dia e melhora dos hábitos vocais devido ao treinamento. (LETHO et al., 2003, MOREIRA et al., 2010)

Pela multifatorialidade envolvida na disfonia, a avaliação de um profissional com alteração vocal requer uma atuação multidisciplinar, envolvendo, na fase do diagnóstico, o otorrinolaringologista, a avaliação fonoaudiológica e do médico do trabalho que, mesmo diante de uma disfonia funcional (sem a evidência de uma lesão), podem entendê-la como um distúrbio de voz relacionado ao trabalho. (CEREST-SP, 2006; BRASIL, 2012) Entretanto, apesar desse problema de voz gerar severas limitações e incapacidade para o trabalho, o fato de não constar na lista de agravos relacionados ao trabalho limita também as garantias para fins previdenciários e securitários. A discussão do protocolo, colocado em consulta pública recentemente, está em fase de compilação e deverá dar as diretrizes para o estabelecimento de condutas voltadas para a vigilância, promoção da saúde, prevenção da doença, diagnóstico, notificação, tratamento e reabilitação do distúrbio da voz relacionado ao trabalho, independentemente do vínculo empregatício e do tipo de inserção do trabalhador no mercado. (BRASIL, 2012)

O uso intensivo da voz foi a exigência/condição de trabalho responsável pelo maior percentual de afastamentos do trabalho: 64,3\% dos teleoperadores que faltaram ao trabalho relataram uso intenso da voz (Tabela 5). A presença de ar condicionado, ambiente frio ou quente demais e estresse no trabalho foram os fatores responsáveis pelos afastamentos observados (respectivamente: $46,4 \%$, 42,9\% e 35,7\%). Como já descrito, esses fatores constituem importantes exposições ocupacionais nessa categoria de trabalhadores, devendo ser propostas medidas para redução, controle ou eliminação dessas exposições.

\section{Considerações finais}

$\mathrm{Na}$ população de teleoperadores estudada, os sintomas vocais mostraram-se frequentes, sendo que aspectos relacionados ao ambiente (presença de ar condicionado, ambiente frio ou quente demais) e à organização do trabalho (uso frequente da voz e estresse no trabalho) foram as causas autorreferidas de maior frequência. A ocorrência de absenteísmo por problema de voz foi elevada, atingindo mais de um terço da população estudada. 
O presente estudo adotou delineamento transversal, sendo realizado por meio de entrevista, com o uso de instrumento estruturado. Todos os aspectos analisados foram autorreferidos pelos trabalhadores. Sabe-se que este tipo de estudo apresenta limitações metodológicas importantes, como o viés recordatório e a inviabilidade de checar a veracidade dos dados, uma vez que nenhuma medida objetiva foi realizada. Adicionalmente, estudos em um único ponto do tempo (transversais) impedem análise de sequência temporal entre os eventos, portanto, não é possível determinar se foram os fatores ambientais e organizacionais que produziram os sintomas vocais ou se esses antecederam a exposição ocupacional.

Cabe também ressaltar que a amostra pesquisada incluiu trabalhadores que procuraram o sindicato com intuitos específicos, como visitas ao serviço médico, o que, consequentemente, pode ter contribuído para a superestimação das frequências dos sintomas investigados. Assim, é importante destacar que os sintomas vocais aqui encontrados não refletem, necessariamente, uma aproximação da realidade dos teleoperadores, mas sim de teleoperadores sindicalizados da cidade do Salvador. Contudo, cabe ressaltar que os resultados aqui encontrados são corroborados por outros estudos que realizaram pesquisa com essa categoria de trabalhadores em outros ambientes laborais. Assim, possíveis vieses de seleção, ainda que não possam ser afastados, parecem não ter influenciado significativamente os achados obtidos.

Outro cuidado na interpretação dos resultados obtidos refere-se à análise descritiva privilegiada neste estudo que focalizou apenas os fatores ocupacionais relacionados aos agravos vocais. Embora tenha sido este o objetivo do estudo, deve-se registrar que outros fatores, além daqueles relacionados ao trabalho podem estar associados aos agravos vocais. Desse modo, estimula-se a realização de estudos futuros com a inclusão, na análise, de outros fatores associados aos agravos vocais, possibilitando uma avaliação mais ampla e rigorosa desses eventos.

Essas limitações do estudo realizado alertam para que os resultados obtidos sejam avaliados com cautela.

É importante salientar a alta ocorrência dos sintomas, que deixa evidente a necessidade de aplicação de medidas que visem controlar fatores ocupacionais nestes ambientes, os quais, certamente, contribuem com o adoecimento do trabalhador. 


\section{Referências}

ALGODOAL, J.; ALOZZA, R. G. Voz na empresa. In: FERREIRA, L. P.; BÉFI-LOPES, D. M.; LIMONGI, S. C. O. Tratado de Fonoaudiologia. São Paulo: Roca, 2004. p. 170-176.

AMORIM, G. O et al. Comportamento vocal de teleoperadores pré e pós-jornada de trabalho. Jornal da Sociedade Brasileira de Fonoaudiologia, v. 23, n. 2, p. 170-176, 2011.

ARAÚJO, T. M.; CERQUEIRA, C. G.; ARAÚJO, E. M. Estresse ocupacional e saúde: contribuições do Modelo Demanda-Controle.

Ciência \& Saúde Coletiva, v. 8, n. 4, p. 991-1003, 2003.

ARAÚJO, T. M. O olhar do sujeito sobre o trabalho que executa: sua percepção sobre os riscos e as tarefas - Um estudo com trabalhadores em telecomunicações. In: SAMPAIO, J. R. (Org.). Qualidade de vida no trabalho e Psicologia Social. 2. ed. São Paulo: Casa do Psicólogo, 2004. p. 367-398.

. et al. Diferenciais de gênero no trabalho docente e repercussões sobre a saúde. Ciência \& Saúde Coletiva, v. 11, n. 1, p. 1117-1129, 2006.

. et al. Fatores associados a alterações vocais em professoras.

Cadernos de Saúde Pública, v. 24, p. 1229, 2008.

BEHLAU, M.; PONTES, P. (org. ). Avaliação e tratamento das disfonias. São Paulo: Lovise, 1995.

BEHLAU, M. et al. Avaliação de voz. In: BEHLAU, M. (org. ). Voz: o livro do especialista. Rio de Janeiro: Revinter, v. 1, 2001. p. 85-245.

. et al. Voz profissional: aspectos gerais e atuação

fonoaudiologia. In: . (org. ) Voz: o livro do especialista.

Rio de Janeiro: Revinter, v. 2, 2005, p. 287-407.

BRASIL. Ministério da Saúde. Protocolo Distúrbio de Voz

Relacionado ao Trabalho. 2012. Disponível em: <http://189. 28.

128. 179:8080/pisast/saude-do-trabalhador/apresentacao/ protocolode-complexidade-diferenciada >. Acesso em: 09 jul. 2012.

. Ministério do Trabalho e Emprego. Código Brasileiro

de Ocupações. Disponível em: <http://www.mtecbo.gov. br/cbosite/pages/home.jsf>. Acesso em: 09 jul. 2012.

. ANEXO II DA NR-17. Portaria SIT n. ${ }^{\circ}$ 09, 30 de março de 2007. Diário Oficial [da] República Federativa do Brasil, 02 abr. 2007. Disponível em: <http:www.mte.gov.br>. Acesso em: 04 jul. 2012. 
BRUSCHINI, M. C. A. Trabalho e gênero no Brasil nos últimos dez anos. Cadernos de Pesquisa, v. 37, n. 132, p. 537-572, 2007.

CEBALLOS, A. G. C. et al. Avaliação perceptivo- auditiva e fatores associados à alteração vocal em professores. Revista Brasileira de Epidemiologia, v. 14, p. 285-295, 2011.

CEREST-SP. Distúrbios de voz relacionados ao trabalho. Boletim Epidemiológico Paulista, Ano 3, n. 26, 2006. Disponível em: http://www. cve.saude.sp.gov.br/agencia/bepa26_dist.htm. Acesso em: 04 jul. 2012.

CHRISTMANN, M. K et al. Características de trabalho e de hábitos e queixas vocais de operadores de telemarketing.

Revista Salusvita, Bauru, v. 29, n. 3, p. 215-228, 2010.

DASSIE-LEITE, A. P.; LOURENÇO, L.; BEHLAU, M. Relação entre dados ocupacionais, sintomas e avaliação vocal de operadores de telesserviços. Revista da Sociedade Brasileira de Fonoaudiologia, v. 16, n. 1, p. 59-63, 2011.

FERREIRA, L. P. et al. Assessoria fonoaudiologia: análise de um processo de construção entre o fonoaudiólogo e o teleoperador. Revista Distúrbios da Comunicação, v. 20, n. 2, p. 219-228, 2008 a.

. et al. Condições de produção vocal de teleoperadores: correlação entre questões de saúde, hábitos e sintomas vocais. Revista da Sociedade Brasileira de Fonoaudiologia, v. 13, n. 4, p. 307-15, 2008 b.

; SANTOS, J. G.; LIMA, M. F. B. Sintoma vocal e sua provável causa: levantamento de dados em uma população. Revista CEFAC. v. 11, n. 1, p. 110-118, 2009.

FUNDAÇÃO EUROPÉIA para a Melhoria das Condições de vida e trabalho. A Preservação do Absentismo no trabalho: sinopse da investigação. Luxemburgo: Serviço das Publicações oficiais das comunidades Europeias, 1997. Disponível em: <www.ourofound.europa. eu/pubdocs/1997/15/pt/1/ef9715pt.pdf>Acesso em: 15 jul, 2012.

GUENA, R. M. Dando voz ao trabalhador: os significados da disfonia para os operadores de telemarketing. Dissertação (Mestrado em Saúde Coletiva) - Universidade Federal da Bahia - instituto de Saúde Coletiva, Salvador, 2009. Disponível em: $<$ http://www. isc.ufba.br/teses.php? externa=2>. Acesso em: 10 jul. 2012.

JONES, K. et al. Prevalence and risk factors for voice problems among telemarketers. Archives of Otolaryngology - Head \& Neck Surgery, v. 128, n. 5, p. 571-577, 2002. 
LETHO, L et al. Experiences of a Short Vocal Training Course for Call-Centre Customer Service Advisors. Folia Phoniatrica Logopaedica, v. 55, p. 163-176, 2003.

. et al. E Voice symptoms of call-centre customer service advisers experienced during a work-day and effects of a short vocal training course. Logopedics Phoniatrics Vocology. Finland, v. 30, n. 1, p. 14-27, 2005.

MARQUES NETO, A. D. Absenteísmo nas empresas. 2006. TCC (Graduação em Administração) Centro Universitário de Brasília - Faculdade de Ciências Sociais Aplicadas. Brasília, 2006. Disponível em: $<$ http://repositorio. uniceub. br/bitstream/ 123456789/2013/1/20401048. pdf. >. Acesso em: 01 jun. 2012.

MONTORO, O. C. P. O estresse na comunicação do telemarketing. 1998. (Monografia de Conclusão do Curso de Especialização em Voz) - Centro de Especialização em Fonoaudiologia Clínica. São Paulo, 1998. Disponível em: <http://www.cefac.br/library/teses/4b2730 58cd37e68efd1a76aba9dd1de8.pdf> Acesso em: 06 jul. 2012.

MOCELIN, D. G.; SILVA, L. F. S. C. O telemarketing e o perfil sócio-ocupacional dos empregados em Call Centers. Caderno CRH, v. 21, n. 53, p. 365-387, 2008.

MOREIRA, T. C. et al. Intervenção fonoaudiologia para consultores em um serviço de teleatendimento: bem-estar vocal. Revista CEFAC, v. 12, n. 6, p. 936-944, 2010.

OLIVEIRA, A. G. A.; BEHLAU, M.; GOUVEIA, N. Vocal symptoms in telemarketers: a random and controlled field trial, Folia Phoniatrica Logopaedica, v. 6, p. 76-82, 2009.

OLIVEIRA JUNIOR, A. M. M. (Coord. ) Relatório da Indústria de Call Centers no Brasil - Programa de Pós Graduação em Administração da PUC-SP, 2005. Disponível em: $<$ http://files. blogdocallcenter.com/200000755666bc6765c/Relatorio_Brasil_GCCP_ V13-versao\%20\%20oficial. pdf >. Acesso em: 09 jun. 2013.

PIWOWARCZYK, T. et al. Sintomas vocais, perfil de participação e atividades vocais (PPAV) e desempenho profissional dos operadores de teleatendimento. In: CONGRESSO Brasileiro de Fonoaudiologia, $18^{\circ}$. Curitiba, 2010. Anais Eletrônicos. Disponível em: <http://www.sbfa. org.br/portal/anais2010/resumos/3651.pdf>. Acesso em: 17 jun. 2012.

PINHO, S. M. R. Manual de higiene vocal para os profissionais da voz. Carapicuíba: Pró-Fono, 1997.

QUICK, T. C.; LAPERTOSA, J. B. Análise do absenteísmo em Usina Siderúrgica. Rev. Bras. Saúde Ocup. , v. 18, n. 69, p. 65-70, 1982. 
SILVA, D. M. P. P.; MARZIALE, M. H. P. Absenteísmo de trabalhadores de enfermagem em um hospital universitário. Rev Latino-Am. Enfermagem, Ribeirão Preto, v. 8, n. 5, p. 44-51, out. 2000.

RATTO, L.; ALBERMAZ, B.; PELTIER, M. Aplicações do telemarketing. In: Telemarketing: comunicação, funcionamento, mercado de trabalho. Rio de Janeiro: SENAC, 2004. Disponível em: http://books. google. com. br/books/ about/TELEMAR KETING_COMUNICA\%C3\%87AO_FUNCIONAMENTO. html?id=BYNkmZ_4ukwC\&redir_esc=y. Acesso em: 10 jul. 2012.

RECHENBERG, L. Prevalência de sintomas vocais em operadores de telemarketing. 2005. Dissertação (Mestrado em Ciências Médicas) Programa de Pós-Graduação em Medicina, Faculdade de Medicina, Universidade Federal do Rio Grande Do Sul. Porto Alegre, 2005. Disponível em: < http:// www.lume.ufrgs.br/handle/10183/15175. > . Acesso em: 09 jul. 2012.

RECHENBERG, L; GOULART, B. N. G; ROITHMANN, R. Impacto da atividade laboral de teleatendimento em sintomas e queixas vocais: estudo analítico. Jornal da Sociedade Brasileira de Fonoaudiologia, v. 23, n. 4, p. 301-307, 2011.

ROCHA, L. E et al. Distúrbios osteomusculares relacionados ao trabalho do ombro entre operadores de central de atendimento telefônico de empresa de transporte aéreo no Brasil. Boletim Saúde. São Paulo, 11 maio 2006. Disponível em: <http://www.sumarios.org/sites/default/ files/pdfs/v19_n1_07disturbiososteom.pdf>. Acesso em: 08 jul. 2012.

SBORL et al. Consenso Nacional sobre Voz Profissional - Voz e Trabalho: uma questão de saúde e direito do trabalhador. Rio de Janeiro, 2004. Disponível em: <http://www.iocmf.com.br/codigos/ consenso2004\%20voz\%20profissional.pdf>. Acesso em: 05 jun. 2012.

SIMBERG, S.; SALA, S.; RONNEMAA, A. M. A comparison of the prevalence of vocal symptoms among teacher students and other university students. J Voice, v. 18, n. 3, p. 363-368, 2004.

SMITH, E. et al. Frequency of voice problems among teachers and other occupations. J Voice, v. 12, n. 4, p. 480-488, 1998.

VILELA, L. V. O.; ASSUNÇÃO, A. A. Os mecanismos de controle da atividade no setor de teleatendimento e as queixas de cansaço e esgotamento dos trabalhadores. Cadernos de Saúde Pública, v. 20, n. 4, p. 1069-1078, 2004.

ZAMBON, K. F. O absenteísmo no Call Center. Monografia. 2009. TCC (Graduação em Administração). Faculdades Metropolitanas Unidas, São Paulo, 2009. Disponível em:< http://arquivo. fmu. br/prodisc/admfmu/kz. pdf>. Acesso em: 01 jun. 2013. 